Asia Pacific Journal of Advanced Business and Social Studies

ISBN (eBook): 9780994365675 । ISSN : 2205-6033

Year: 2018 , Volume: 4, Issue: 1

\title{
THE EFFECT OF USER ACCEPTANCE ON CONTINUANCE INTENTION FORONLINE SHOPPING (RESEARCH ON INSTAGRAM USER)
}

\author{
Brian Gregory Adhihendra a ,Sahid Susilo Nugroho ${ }^{b}$ \\ ${ }^{a b}$ Gadjah Mada University, Yogyakarta, Indonesia \\ Corresponding email: brianadhihendra@gmail.com
}

\begin{abstract}
Over time, the development of information and technology have an impact on the everexpanding variety of events and activities associated with the use of the internet, especially on the use of social media. The development of social media opensopportunities for marketers and researchers to research the factors that lead to social media usage behavior. A Deep understanding of the factors that affect the use of social media will be very useful for consumers and marketers. This research focuses on testing the effect of the five dimensions of personality traits that is extraversion, conscientiousness, openness to experience, neuroticism, and agreeableness andperceived ease of use on perceived usefulness. Furthermore, the effect ofperceived usefulness on continuance intention are examined. Using purposive sampling, the object of thisresearch is Instagram users. Data collection and analyses was started in November 2016, and finished in January 2017. Total 230 Instagram user from different region in Indonesia, are collected as the data. Using Structural Equation Modeling (SEM) with AMOS software, data analyses revealed that some of the dimensions of personality traits and perceived ease of use have significant effect on perceived usefulness, while the latter have significant effect on continuance intention for online shopping. Theoritical and practical implications of the findings, and future research suggestions are also discussed inthe last part of the research.
\end{abstract}

Keywords: Personality Traits, Perceived Ease of use, Perceived Usefulness, Continuance Intention, Instagram.

\section{Introduction}

Over time, the development of information and technology have an impact on the everexpanding variety of events and activities associated with the use of the internet, especially on the use of social media. The development of social media opens opportunities for marketers and researchers to research the factors that lead to social media usage behavior. Deep understanding of the factors that affect the use of social media will be very useful for consumers and marketers. Social media is defined asa group of internet-based applications that build on the ideological and technologicalfoundation of Web 2.0, and that allow the creation and exchange of User Generated Content (Kaplan dan Haenlein, 2010). The use of social media (e.g., Facebook, LinkedIn, Youtube, Twitter) has grown significantly among consumers. People spend more time on social media than any other category of sites, with an average of 121.18 min per day in 2012, which represents an increase of $37 \%$ with respect to the previous year.

Other than governmental and political, educational, and marketing perspectives, social media usage and analysis of user behaviors are also one of the most popular topics in the academic world(Akar and Mardikyan, 2014). The development of social media open opportunities for marketers and researchers to research the factors that lead to social media 
usage behavior. A Deep understanding of the factors that affect the use of social media will be very useful for consumers and marketers (Sriyabhand and John, 2014).

Earlier studies demonstrated the link between personality and the Internet, providing support for the initial suggestion that the variance in use of the Internet depend on personality traits. (Kabadayi and Price, 2014; Akar and Mardikyan, 2014; Devaraj and Easley, 2008) This line of research determined that various personality traits were significantly related to online activities in general. (Amichai-Hamburger, 2002; Kabadayi and Price, 2014).

In this research, we investigate the relationship between five personality traits and perceived ease of use to perceived usefulness. Furthermore, the effect between perceived usefulness on continuance intention are examined. We believed that our findings may shed light on understanding the personality factor that lead consumers to perceived usefulness on Instagram, and lead consumers to their continuance intention for online shopping using Instagram, thus helping companies improve the effectiveness of their brand strategies on social media.

\section{Theoritical Developments and Hypothesis}

\subsection{Personality Traits}

Personality is a dynamic organisation within the individual of those psychophysical systems that determine his characteristic behaviour and thoughts'. Personality development is affected by several factors including heredity, social environment, family, geographical and physical condition etc. (Ozbek et al., 2014). There are five personality traits that are calledbig-five personality traits, that is:

\subsubsection{Extraversion}

Extroverts are expected to meet others and more easily and engage in more social interactions. Similarly, individuals with low levels of extraversion tend to be more introverted, inhibited, shy, submissive, and inactive, reserved and prefer to spend more time alone or stay within close circles (Sriyabhand and John, 2014). The extrovert is a friendly person who seeks company, desires excitement and acts on impulse, whereas the introvert is a quiet, reflective person who prefers his or her own company and does not enjoy large social events; he or she does not crave excitement. The level of extraversion has been found to play a significant role in online communication experiences (Kabadayi and Price, 2014)

\subsubsection{Conscientiousness}

Sriyabhand and John (2014) suggested that individuals scoring high in conscientiousness can be described as motivated and careful. Barrick and Mount (2001) found that conscientiousness is associated with dependability and achievement striving. Therefore, conscientiousness is expected to have a positive effect on performance in the workplace and educational performance in the context of education and learning.

\subsubsection{Openness to experience}

Openness to experience represents an individual's willingness to consider alternative approaches, be intellectually curious and enjoy artistic pursuits (Kabadayi and Price, 2014). McCrae, (1996) suggested that openness to experience may have the strongest effect on social and interpersonal phenomena among all five traits under comparison. People who arehigh in openness are more likely to have a blog and communicate with others over internet (Guadagno et al., 2008). Since the individuals described as high in openness to experience are curious and are willing to try new and different things (Devaraj and Easley, 2008).

\subsubsection{Neuroticism}

Neuroticism reflects a person's tendency to experience psychological distress and a high level of sensitivity to threat. The neurotic person is an anxious, worrisome individual who is overly 
emotional and reacts to all types of stimuli (Ross et al., 2009). Devaraj and Easley (2008) suggested that neurotic individuals are expected to view technological advancements as threatening and stressful for their daily routine. One of the central measures of neuroticism is lack of emotional stability. It has been found that those who are high in this trait are likely to use the Internet to avoid loneliness, limiting their interaction to only those who they personally know (Kabadayi and Price, 2014).

\subsubsection{Agreeableness}

Agreeableness is strongly related to the beliefs in technology when that technology supports participation, cooperation, and task accomplishment. Agreeableness is the desired characteristics most individuals would consider in a communications partner. Therefore, it is expected that people high in these characteristics are more likely to engage in a conversation in any of the available medium. (Devaraj et al., 2008).Mouakket (2015) argue that agreeable individuals are more likely to consider social networking technology useful, as it would help them foster their personal relationship with others.

\subsection{Perceived Usefulness}

Consumers with extraversion are socialist, firm, optimistic, and active. Social networking sites are considered by an extrovert as a way of asserting themselves and thus, can be considered quite useful (Mouakket, 2015). Social networking allows an extrovert to communicate with their friends anytime and anywhere. This will then affect perceptions of the perceived usefulness of these consumers (Walczuch and Lundgren, 2004). Thus, we hypotized that:

\section{H1: Extraversion positively related to perceived usefulness}

Consumers with conscientiousness are consumers with efficient self-control, organized, and tend to find different methods to use technology that enables them to improve their performance (Mouakket, 2015). The researchers argue that conscientiousness consumers who perceive useful information systems tend to have a positive intention to use technology than consumers who have no conscientiousness (Devaraj et al., 2008). Thus, we hypotized that:

H2: Conscientiousness positively related to perceived usefulness

Consumers with openness are intellectual consumers, willing to accept new and creative ideas (Mouakket, 2015). Research finds that consumers with openness tend to be creative and intellectual, so social networking sites can be considered as a new experience to connect with their friends (Rosen and Kluemper, 2008). Thus, we hypotized that:

H3: Openness to experience positively related to perceived usefulness

Consumers with neuroticism are worried consumers, hostile, frightened and depressed (Judge and Bono, 2000). They see new technology as threatening and stressful, therefore they tend to have negative feelings on perceived usefulness (Devaraj et al., 2008). Our next hypotized is:

H4: Neuroticism negatively related to perceived usefulness

Consumers with agreeableness are polite, flexible, cooperative, soft-hearted, and tolerant. Consumers with agreeableness tend to seek useful social media, as it will help their personal relationships with others (Mouakket, 2015). Then, we hypotized that:

$\mathrm{H}_{5}$ : Agreeableness positively related to perceived usefulness

\subsection{Perceived Ease of Use}

Perceived ease of use is defined as the degree to which a person believes that using a particular system would be free from effort (Davis, 1989; Ozbek et al., 2014). Ease of use refers to the freedom from the difficulty or greater effort of using a system. It is assumed that 
if an application is perceived to be easier to use than another, then it is more likely to be accepted by its users (Sriyabhand and John, 2014).

The importance of perceived ease of use explains the extent to which an innovation is considered not difficult to understand, to research, and to use (Rauniar et al., 2014). In the context of social media, users may judge a site based on the ease of the site for use and how effectively it helps to meet their social media needs (Rauniar et al., 2014). Thus, we hypotized that:

H6: Perceived ease of use positively related to perceived usefulness

\subsection{Continuance Intention}

Bhatttacherjee (2001) explains that consumers tend to intend or repeat buying when a perceived use has benefits. Al-maghrabi et al. (2011) suggests a useful online product can make consumers experience higher enjoyment at online stores. As a result, these consumers will use and recommend to their peers. While this may not affect their friends, the perception of utility may encourage their friends to recommend by word of mouth. This will increase their continuance intention (Chung and Tan, 2004). Our final hypotisis is:

H7: Perceived usefulness positively related to continuance intention

\section{Research Model}

Based on the comprehensive evaluation of the previous literature (Kabadayi and Price, 2014; Ozbek et al., 2014; Al-maghrabi et al., 2011), related to FFM (Costa and McCrae, 1992), and TAM (Davis, 1989), a conceptual research model is developed. The model consists of eight different constructs, namely extraversion, conscientiousness, openness to experience, neuroticism, agreeableness, perceived usefulness, perceived ease of use, and continuance intention. The proposed research model (See Figure 1) below.

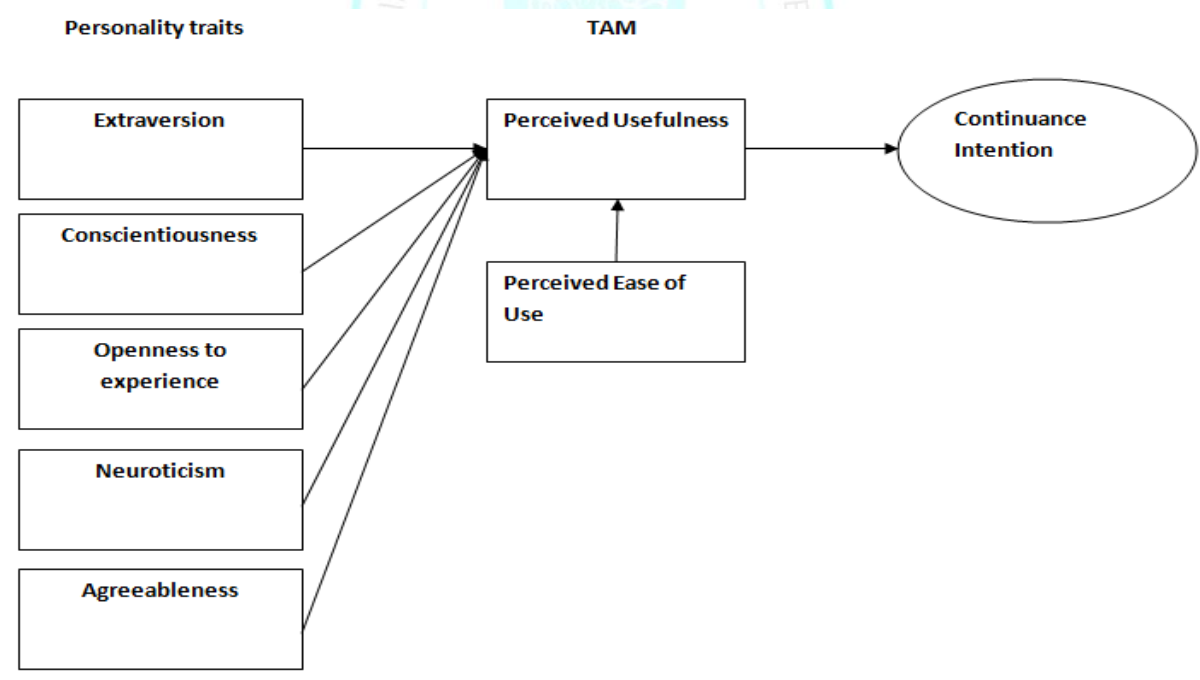

Figure 1: Proposed Research Model

\section{Methodology}

\subsection{Population and Sampling}

This research was conducted in Indonesia. Theresearch population consists of Instagram users in Indonesia. This research sample is Instagram users who had experience withshopping online through Instagram in one year. Purposive sampling method, one of the probability sampling methods, was used in this research. A total of 230 Instagram users completed our questionnaire distributed through offline and online survey tools. 


\subsection{Research Methodology}

The research employed survey methods to carry out the data collection and measurement process. Traditional paper based questionnaires, as well as online questionnaires were used to collect the data from the Instagram users in Indonesia. The online questionnaire was created using a Google form and the link was published in any social networking. This saved the time of data collection incredibly.

Sample size plays an important role in statistic (Hair et al., 2010) and was the major data analysis tool we used in this research. The sample estimation guidelines according to Hair et al. (2010) is determined at $100-200$ sample. To perform a factor analysis requires a minimum sample that is 50 , but preferably if the sample size is 100 or more (Hair et al., 2010). Our sample size is 230 respondents which matches with the minimum requirements of Structural Equation Modelling (SEM) by Hair et al. (2010).

Regarding the measurement items, all the measuring instruments were taken from previously validated literatures related to personality, technology adoption, and continuance intention researchs. Measuring instruments from FFM were taken from Kim and Chung (2014) and Kabadayi and Price (2014). The measuring instruments from perceived usefulness and perceived ease of use were adapted from Rauniar et al. (2014). The measuring instruments from continuance intention were taken from Al-maghrabi et al. (2011). All items were measured using a five-point Likert scale ranging from 1 (strongly disagree) to 5 (strongly agree).

\section{Data Analysis and Results}

Structural Equation Modelling (SEM) has been employed to test the conceptual model in our research. In its general form, SEM consists of two parts: the measurement of instruments and the data analysis.

\subsection{The Measurement of Instruments}

The overall fit of the measurement model, adequacy of the factor loadings, explained variances of the measurement model were determined by the Confirmatory Factor Analysis (CFA) using SPSS version 16. One item was deleted based on the non-significant or poor loading estimates (below 0.5). Table 1 demonstrates the validity of the constructs:

Table 1: Validity Analysis Results

\begin{tabular}{|c|c|c|c|c|}
\hline Variable & Mean & $\begin{array}{l}\text { Standard } \\
\text { Deviation }\end{array}$ & Items & $\begin{array}{c}\text { Factor } \\
\text { Loading }\end{array}$ \\
\hline \multirow{6}{*}{ Extraversion } & \multirow{6}{*}{3.91} & \multirow{6}{*}{0.617} & EKS1 & 0.703 \\
\hline & & & EKS2 & 0.835 \\
\hline & & & EKS3 & 0.776 \\
\hline & & & EKS4 & 0.827 \\
\hline & & & EKS5 & 0.761 \\
\hline & & & EKS6 & 0.836 \\
\hline \multirow{6}{*}{ Conscientiousness } & \multirow{6}{*}{4.08} & \multirow{6}{*}{0.590} & BER1 & 0.617 \\
\hline & & & BER2 & 0.845 \\
\hline & & & BER3 & 0.874 \\
\hline & & & BER4 & 0.883 \\
\hline & & & BER5 & 0.781 \\
\hline & & & BER6 & 0.633 \\
\hline \multirow{5}{*}{$\begin{array}{c}\text { Openness to } \\
\text { Experience }\end{array}$} & \multirow{5}{*}{3.71} & \multirow{5}{*}{0.581} & KET1 & 0.754 \\
\hline & & & KET2 & 0.849 \\
\hline & & & $\mathrm{KET}_{3}$ & 0.852 \\
\hline & & & KET4 & 0.749 \\
\hline & & & KET5 & 0.606 \\
\hline
\end{tabular}




\begin{tabular}{|c|c|c|c|c|}
\hline \multirow{6}{*}{ Neuroticism } & \multirow{6}{*}{2.70} & \multirow{6}{*}{0.718} & NEU1 & 0.728 \\
\hline & & & NEU2 & 0.705 \\
\hline & & & $\mathrm{NEU}_{3}$ & 0.806 \\
\hline & & & NEU4 & 0.758 \\
\hline & & & NEU5 & 0.707 \\
\hline & & & NEU6 & 0.582 \\
\hline \multirow{5}{*}{ Agreeableness } & \multirow{5}{*}{3.59} & \multirow{5}{*}{0.544} & KER2 & 0.631 \\
\hline & & & KER3 & 0.800 \\
\hline & & & KER4 & 0.688 \\
\hline & & & KER5 & 0.606 \\
\hline & & & KER6 & 0.741 \\
\hline \multirow{5}{*}{$\begin{array}{c}\text { Perceived Ease of } \\
\text { Use }\end{array}$} & \multirow{5}{*}{4.16} & \multirow{5}{*}{0.614} & KEM1 & 0.636 \\
\hline & & & KEM2 & 0.836 \\
\hline & & & KEM3 & 0.870 \\
\hline & & & KEM4 & 0.861 \\
\hline & & & KEM5 & 0.870 \\
\hline
\end{tabular}

\begin{tabular}{|c|c|c|c|c|}
\hline Variable & Mean & $\begin{array}{l}\text { Standard } \\
\text { Deviation }\end{array}$ & Items & Factor Loading \\
\hline \multirow{5}{*}{$\begin{array}{c}\text { Perceived } \\
\text { Usefulness }\end{array}$} & \multirow{5}{*}{3.67} & \multirow{5}{*}{0.740} & KEG1 & 0.693 \\
\hline & & & KEG2 & 0.716 \\
\hline & & & KEG3 & 0.805 \\
\hline & & & $\mathrm{KEG}_{4}$ & 0.805 \\
\hline & & & KEG5 & 0.695 \\
\hline \multirow{5}{*}{$\begin{array}{l}\text { Continuance } \\
\text { Intention }\end{array}$} & \multirow{5}{*}{3.50} & \multirow{5}{*}{0.737} & NL1 & 0.832 \\
\hline & & & $\mathrm{NL} 2$ & 0.862 \\
\hline & & & NL3 & 0.836 \\
\hline & & & NL4 & 0.880 \\
\hline & & & NL5 & 0.826 \\
\hline
\end{tabular}

Reliability analysis (Refer table 2) of the multi item-scales resulted favorable results. The Cronbach's Alpha values were calculated for each construct. Alpha ranging from 0.749 0.940 indicate that high overall internal consistency among the items under each of the construct.

Table 2: Reliability Analysis Results

\begin{tabular}{|c|c|}
\hline Constructs & Cronbach's Alpha \\
\hline Extraversion & 0,885 \\
\hline Conscientiousness & 0,882 \\
\hline Openness the experience & 0,832 \\
\hline Neuroticism & 0,815 \\
\hline Agreeableness & 0,749 \\
\hline Perceived Usefulness & 0,898 \\
\hline Perceived Ease of Use & 0,928 \\
\hline Continuance Intention & 0,940 \\
\hline
\end{tabular}




\subsection{The Data Analysis}

Further analysis utilized the Structural Equation Modeling (SEM) techniques via AMOS 18 program. Once the fit of the measurement model has been confirmed, the fit of the structural path were evaluated. The SEM helped to identify the efficacy of the model and test the proposed hypotheses. Results exhibited good fit $(\mathrm{RMSEA}=0,055 ; \mathrm{CFI}=0,901 ; \mathrm{CMIN} / \mathrm{DF}=$ 1,702) of the structural model. The structural equation parameters estimates provide empirical support for the hypotheses proposed. Results of the hypotheses tested are given inTable 3:

Table 3: Hypothesis Analysis Results

\begin{tabular}{|r|l|l|l|l|}
\hline No. & \multicolumn{1}{|c|}{ Hypotheses } & C.R. & Estimate & Kesimpulan \\
\hline 1 & $\begin{array}{l}\text { H1: Extraversion positively related } \\
\text { to perceived usefulness }\end{array}$ & 0,852 & 0,050 & Not Supported \\
\hline 2 & $\begin{array}{l}\text { H2: Conscientiousness positively } \\
\text { related to perceived usefulness }\end{array}$ & 1,084 & 0,118 & Not Supported \\
\hline $\begin{array}{l}\text { H3: Openness to experience } \\
\text { positively related to perceived } \\
\text { usefulness }\end{array}$ & $1,963^{*}$ & 0,208 & Supported \\
\hline 4 & $\begin{array}{l}\text { H4: Neuroticsm negatively related } \\
\text { to perceived usefulness }\end{array}$ & $2,076^{*}$ & 0,159 & Not Supported \\
\hline 5 & $\begin{array}{l}\text { H5: Agreeableness positively related } \\
\text { to perceived usefulness }\end{array}$ & 0,592 & 0,046 & Not Supported \\
\hline 6 & $\begin{array}{l}\text { H6: Perceived ease of use positively } \\
\text { related to perceived usefulness }\end{array}$ & $6,486^{*}$ & 0,478 & Supported \\
\hline 7 & $\begin{array}{l}\text { H7: Perceived usefulness positively } \\
\text { related to continuance intention }\end{array}$ & $7,723^{*}$ & 0,668 & Supported \\
\hline
\end{tabular}

\section{Discussion and Conclusion}

The purpose of this research is to examine the effect of dimension of personality traits that is extraversion, conscientiousness, openness to experience, neuroticism and agreeableness, and perceived ease of use toward perceived usefulness, then examining perceived usefulness toward continuance intention. Based on the results of the analysis of research findings, it can be concluded that the continuance intention is formed by perceived usefulness. While the perceived usefulness is effected by the openness to experience, neuroticism and the perceived ease of use.

Extraversion has no significant effect on perceived usefulness. Consumers with high extrovert such as socialist, assertive, optimistic, and active consumers will not necessarily affect their perceived usefulness of Instagram. Sullivan (2012) explains the effect of extraversion on the perceived usefulness associated with risk, namely that consumers with extroverted properties tend to take risks, preferring to perceive the ease of using Instagram rather than the usefulness of Instagram itself.

Concientiousness does not have a significant effect on perceived usefulness. Consumers with high conscientiousness such as efficient and organized self-control will not necessarily affect the perceived usefulness of Instagram. Barrick and Mount's (1991) and Sullivan (2012) explain the effect of conciensiousness on perceived usefulness in relation to the characters of consumers who tend to seek to reach decisions taken. So, consumers with high concientiousness when using Instagram do not perceive usefulness or ease of use, because they tend to focus on achieving their decisions without regard to and feel the usefulness or benefits of Instagram.

Openness to experience has a significant effect on perceived usefulness. Consumers with high openness such as intellectual consumers, willing to accept new ideas, and creative, will increase consumer perceived usefulness level on Instagram. Consumers will feel and 
perceive the benefits or usefulness of social media Instagram if the social media is perceived to increase their insight, experience, and creativity.In accordance with the research of Rosen and Kluemper (2008) which explains that consumers with openness to experience tend to be creative and intellectual, so social networking sites can be considered as a new experience to connect with their friends.

Neuroticism has a significant positive effect on perceived usefulness. The higher the consumer with neuroticism such as worry, hostility, fear and depression will increase the perceived usefulness level of consumer on Instagram. These consumers will lower the perceived usefulness of social media use on Instagram if the social media is perceived to be threatening, frightening, stressful, and not beneficial to them. This is in accordance with Sullivan (2012) who proposed the hypothesis that the neuroticism has a positive effect on perceived usefulness. The research explains that neuroticism has a positive effect on perceived usefulness. Sullivan (2012) and Wang and Yang (2005) explains that consumers with the neuroticism is an unstable consumer, easily frightened, depressed, and irritable. Social pressures theoretically cause consumers with neuroticism to exhibit certain behaviors. So if a social media is perceived by a consumer with high neuroticism can be entertaining (Sullivan, 2012, Wang and Yang, 2005) or help to complete the task (Raja et al., 2004), then the consumer will feel that the social media is beneficial for them.

Agreeableness does not have a significant effect on perceived usefulness. Consumers with high agreeableness traits such as courteous, flexible, cooperative, gentle, and tolerant will not necessarily affect their perceived usefulness of Instagram. Ames and Bianchi(2008)suggests the influence of agreeableness on perceived usefulness in relation to the agreableness. Consumers with agreeableness traits will likely bring agreableness to people or other media who are interacting with them. So, if someone who sees themselves as a friendly person, their colleagues interact should have friendly to them as well. So, if consumers with agreeableness feel unfriendly to them in using Instagram, then they will not feel the benefits or usefulness of Instagram itself.

Perceived ease of use has a significant influence on perceived usefulness. The easier the innovation to understand, learn, and use it will increase the perceived usefulness of a technology. The higher the ease of use of Instagram, it will increase their perceived usefulness or benefits of social media Instagram it. In accordance with Rauniar et al. (2014) who argue that in the context of social media, consumers may judge a site based on the ease of the site to use. So, after consumers feel Instagram is easy to use, then they will perceive that Instagram will be useful and useful for their lives.

Perceived usefulness has a significant effect on continuance intentions. The more useful a technology will be to increase the intention of either to use or make a transaction through the technology. Consumers who increasingly feel the usefulness or benefits of Instagram social media, it will increase the likelihood they will continue the purchase through social media Instagram.

\section{Research Implications}

The implications of these results for practitioners are important. Due to the popularity of the social media Instagram, most of the businesses are actively engaging in social media Instagram to get the customer's attention. The practical implication of this research is to identify the different traits of Instagram users. Having knowledge about the personality traits of the Instagram users will help the marketers to design their advertisement and other communication tools more effectively. For the academic world, this research contributes by providing an empirically validated literature specifying the relationship between personality traits, technology adoption behavior, and continuance intention for buy using Instagram.

\section{Limitations and Future Research Directions}

This research has some limitations. The research object used in this research is focused on one type ofsocial media that is Instagram. Therefore,that impact on the generalization of 
studies are limited. Future research should be examined on different objects and can also compare some other social media so that the concept can be improved generalized model and provide a broader picture of the consumer's continuance intentions on social media.

This research is cross sectional, that is done at one point of time, so it can not capture with good behavior change or intention that happened to consumer considering very rapid change that happened through technological development. To be able to know the variation of the research results, then the next research should conduct a continuous survey (longitudinal), with a continuous survey is expected to explain the phenomenon that occurs in consumers and the development of the social media world better. 


\section{References}

i. $\quad$ Akar, E., \& Mardikyan, S. (2014), “Analyzing Factors Affecting Users ' Behavior Intention to Use Social Media : Twitter," International Journal of Business and Social Science, Vol. 5(11), pp. 85-95.

ii. Al-maghrabi, T., Dennis, C., Halliday, S. \& BinAli, A. (2011), "Determinants of Customer Continuance Intention of Online Shopping," International Journal of Business Science and Applied Management, Vol. 6(1).

iii. Ames, D., \& Bianchi, E., (2008), "The Agreeableness Asymmetry in First Impressions: Perceivers Impulse to (Mis)judge Agreeableness and How it is Moderated by Power," Personality and Social Psychology Bulletin, Vol. 34(12).

iv. Barrick, M. R., \& Mount, M. K. (1991), "The big five personality dimensions and job performance: A meta-analysis" Personnel Psychology, Vol.44(1), pp. 1-26.

v. Bhattacherjee, A. (2001), "Understanding information systems continuance: An expectationconfirmation model," MIS Quarterly., Vol. 25(3), pp. 351-370.

vi. Costa, P. T. \& McCrae, R. R. (1992), "Normal personality assessment in clinical practice: The NEO Personality Inventory," Psychological Assessment, Vol. 4(1), pp. 5-13.

vii. Davis, F. (1989), "Perceived Usefulness, Perceived Ease of Use, and User Acceptance of Information Technology," MIS Quarterly, Vol. 13(3), pp. 319-340

viii. Devaraj, S. \& Easley, R. (2008), "How does personality matter? Relating the five-factor model to technology acceptance and use," Information Systems Research, Vol.19(1), pp. 93-105

ix. Guadagno, R. E., Okdie, B. M., \& Eno, C. A. (2007), "Who blogs? Personality predictors of blogging," Computers in Human Behavior, pp. 1-12.

x. Hair Jr, J. F., Black, W.F., Babin, B. J. \& Anderson, R. E. (2010), Multivariate Data Analysis, A Global Perspective, 7th edition, Upper Saddle River, New Jersey: Pearson Education, Inc.

xi. Judge, T. A., \& Bono, J. E. (2000), "Five-factor model of personality and transformational leadership," Journal of Applied Psychology, Vol. 85, pp. 751- 765.

xii. Kabadayi, S., \& Price, K. (2014), "Consumer - brand engagement on Facebook : liking and commenting behaviors," Journal of Research in Interactive Marketing,8(3), pp. 203-223.

xiii. Kaplan, A. M. \& Haenlein, M. (2010), "Users of the world, unite! the challenges and opportunities of social media," Business Horizons, Vol. 53(1), pp. 59-68.

xiv. McCrae, R. R. (1996), "Social consequences of experiential openness," Psychological Bulletin, Vol. 120(3), pp. 323-337.

xv. Mouakket, S. (2015), "Perceived Usefulness of Facebook: Effects of Personality Traits and Gender," Journal of Advance in Information Technology, Vol. 6(3), pp. 111-117.

xvi. Özbek, V., Aln, Ü., Koc, F., Akk, M. E., \& Ka, E. (2014)," The Impact of Personality on Technology Acceptance : A Study on Smart Phone Users," Social and Behavioral Sciences, Vol. 150, pp. 541-551.

xvii. Rauniar, R., Rawski, G., Yang, J., \& Johnson, B. (2014), "Technology acceptance model (TAM) and social media usage: an empirical study on Facebook," Journal of Enterprise Information Management, Vol. 27(1), pp. 6 - 30.

xviii. Ross, C., Orr, E., Sisic, M., Areseneault, J., Simmering, M., \& Orr, R. (2009), "Personality and motivations associated with Facebook use," Computers in Human Behavior, Vol. 25, pp. 578586.

xix. Wang, H. I., \& Yang, H. L. (2005), “The role of personality traits in UTAUT model under online stocking," Contemporary Management Research, Vol.1(1), pp. 69-82. 
xx. Sriyabhand, T., \& John, S. P. (2014), "An Empirical Study about the Role of Personality Traits in Information Technology Adoption," Journal of Social Sciences, Humanities, and Arts, Vol. 14(2), pp. 67-90.

xxi. Sullivan, M. (2012). "A Study of The Relationship Between Personality Types and The Acceptance of Technical Knowledge Management Systems (TKMS)," Capella University.

xxii. Walczuch, R., \& Lundgren, H. (2004), "Psychological antecedents of institution-based consumer trust in e-retailing," Information \& Management, Vol.42(1), pp. 159-177. 